\title{
The Right to Health
}

\author{
From Treatment and Care to \\ Creating the Conditions for a Healthy Life
}

\author{
SOUTH AFRICA: HOW A CONSTITUTIONAL \\ RIGHT TO HEALTH PREVENTED HUNDREDS OF \\ THOUSANDS OF HIV CASES
}

At one month old, Busisiwe Maqungo's daughter Nomazizi became seriously ill, ${ }^{1}$ suffering from dehydration, diarrhea, and pneumonia. When Busisiwe took her to the hospital, the doctor delivered two potentially life-threatening diagnoses: Busisiwe was HIV-positive, and Nomazizi was too.

Although Busisiwe had been tested for HIV during an antenatal care visit in Cape Town, the nurse who administered the test neither informed her of its purpose nor disclosed the positive result-and certainly did not offer Busisiwe treatment that could avert the transmission of HIV to her unborn child. Busisiwe already knew from television that there were drugs that could prevent mother-tochild transmission of HIV, but had no reason to think this applied to her own pregnancy. After Nomazizi's diagnosis, Busisiwe borrowed money to pay for countless trips to the hospital, where doctors told her there was nothing they could do and that Nomazizi would die. Eight months later, she did.

In the late 199os, stories like Busisiwe's were far too common in South Africa. By 1998, approximately 70,000 infants across the country were contracting HIV 
from their mothers annually. ${ }^{2}$ The manufacturer of Nevirapine, a drug found to prevent mother-to-child transmission, offered it for free to South Africa for a fiveyear period. Nevertheless, although the World Health Organization (WHO) and South Africa's Medicines Control Council deemed Nevirapine safe, the government chose to provide it only at a select number of private-sector pilot sites, making it impossible for public-sector doctors to prescribe it for patients in need.

Nomazizi's death devastated Busisiwe. Yet she realized that numerous women were having similar experiences, which could be prevented by a government commitment to ensuring universal access to anti-retroviral drugs. To help make this a reality, Busisiwe joined the Treatment Action Campaign (TAC), a South African activist organization that had long advocated for people with HIV/AIDS, including by leading a campaign to reduce the price of patented drugs used to treat HIV.

In 2001, following years of advocacy outside the courts, TAC initiated a lawsuit against the South African government, arguing that its failure to provide comprehensive services to prevent mother-to-child HIV transmission violated the right to healthcare services in the 1996 constitution. Along with several other women, Busisiwe told her story in an affidavit, helping TAC build a compelling case grounded in the experiences of South African mothers.

In July 2002, South Africa's Constitutional Court handed down a groundbreaking decision in the TAC case, finding that the constitutional right to health "require[d] the government to devise and implement within its available resources a comprehensive and co-ordinated programme to realize progressively the rights of pregnant women and their newborn children to have access to health services to combat mother-to-child transmission of HIV."3 Further, the Court specifically ordered the state to remove restrictions on Nevirapine's availability at public hospitals and clinics. ${ }^{4}$

Since the TAC case, many more women in South Africa have received access to drugs to prevent mother-to-child HIV transmission. ${ }^{5}$ While the Court's order has not been perfectly or universally implemented, this litigation ultimately prevented hundreds of thousands of HIV infections. ${ }^{6}$ Globally, the case provided one of the most powerful illustrations of how social movements can leverage constitutional health rights to produce meaningful change.

\section{INDIA: STRENGTHENING ACCESS TO HEALTHCARE BEFORE AND AFTER BIRTH, REGARDLESS OF INCOME}

As the TAC litigation was unfolding, in other parts of the world, a movement was building to apply a human rights approach to mothers' survival.? At the international level, a 2009 U.N. Human Rights Council resolution acknowledged that ending preventable maternal mortality would require "the effective promotion and protection of the human rights of women and girls," including the right "to enjoy 
the highest attainable standard of physical and mental health, including sexual and reproductive health." ${ }^{\text {At }}$ the national level, lawyers and civil society were increasingly turning to constitutional protections to apply this rights-based approach to protecting women's health before, during, and after childbirth.

Some of the most groundbreaking cases were taking place in India. Notably, unlike South Africa, India has no explicit "right to health" in its constitution. However, Article 21's protection of the "right to life" has come to embody an expansive legal protection for medical services, a healthy environment, and access to essentials for a healthy life. Constitutional protections of the "right to life" have advanced the right to health in some countries and created potential threats to individual health and healthcare decision-making in others. In India, however, advocates have successfully leveraged Article 21 in wide-ranging health-related matters, including a "right to food" case that dramatically expanded access to free school lunch" and an air pollution case that yielded important new regulations promoting the use of clean fuels. ${ }^{10}$ Within the past decade, the health protections encompassed by the right to life have provided powerful tools to promote accountability for the preventable deaths of poor women during childbirth because of inadequate medical services.

\section{Exclusion from Basic Care and Services}

On a hot day in May 2009, Fatema ${ }^{11}$ went into labor beneath the tree where she herself had been born 21 years earlier, ${ }^{12}$ in an open area steps from the Nizamuddin Dargah, a popular Delhi mausoleum frequented by thousands weekly. ${ }^{13}$ Fatema lived in the open space with her mother Jaitun, a retired laborer in her sixties, along with a number of other homeless families. Abandoned by her husband upon becoming pregnant, Fatema had turned to her mother for support throughout her pregnancy. With only the tree's boughs offering any protection from the elements, Fatema gave birth to a baby girl, Alisha, in full view of passersby and without any professional help. ${ }^{14}$

This was not by choice. Fatema had tried, repeatedly, to access the care she needed - and qualified for. ${ }^{15}$ Given her epilepsy, which caused regular seizures, she had known she faced additional medical risks. Twice while pregnant, she visited a government-run maternity hospital near where she lived, inquiring about the cash assistance she could receive upon giving birth there through the Janani Suraksha Yojana (JSY) program. Both times, her questions were ignored, her pregnancy went unregistered, and medical staff made no effort to provide her with the other prenatal services, benefits, and nutrition for which all poor pregnant women in India are eligible.

Shortly after Fatema gave birth outside, Jaitun once again went to the maternity hospital, alerting staff to the delivery and requesting an ambulance. Yet no ambulance was dispatched, and no hospital staff visited. In the ensuing weeks, the frustra- 
tions mounted: Fatema was able to get Alisha vaccinated at the maternity hospital in early June, but the child received no checkup. Hospital staff told Fatema she was anemic, but conducted no blood tests. Fatema, who was illiterate, received from the hospital the discharge slip she needed to get her JSY benefits, but it was written in English and she was unable to understand the actions required. She visited the hospital repeatedly seeking the benefits, but was refused. Finally, with an activist's help, Fatema collected 550 rupees from the hospital-around 8-9 U.S. dollars. ${ }^{16}$

In the following months, both Fatema's and Alisha's health deteriorated. Without adequate nutrition, Fatema could not breastfeed, and had no money to buy milk. Alisha was going hungry during the most critical time of her development. Despite having repeated contact with a government hospital during and after her pregnancy, neither Fatema nor Alisha received the assistance designed to help impoverished mothers and their children. ${ }^{17}$

Finally, as their circumstances grew truly desperate, Fatema and her daughter connected with legal assistance and discovered that they could initiate a case against the maternity hospital for its failure to provide care. In interim orders, the Delhi High Court ordered immediate relief for Fatema and Alisha: Alisha would receive the nutritional benefits provided by the Integrated Child Development Scheme; Alisha and Fatema would receive their ration card for grains and oil; Fatema would receive the cash assistance guaranteed by the National Maternity Benefit Scheme; and both would receive a checkup at the maternity hospital, accompanied by social workers, and have access to an ambulance in case further treatment at the primary hospital was necessary. ${ }^{18}$

The Court did not stop there. A few months before hearing Fatema's case, the presiding judge, Justice Muralidhar, had heard arguments in a similar case, Laxmi Mandal v. Deen Dayal Harinagar Hospital. ${ }^{19}$ The case had been brought by the brother of an impoverished woman, Shanti Devi, who was also denied the care she was entitled to and died just minutes after giving birth. To address issues common to both cases, Justice Muralidhar issued a joint decision the following summer. In June 2010, the Delhi High Court established for the first time that India's constitution protects the right to maternal health-thus obligating the government to ensure all pregnant women and new mothers can access the services they need. As the Court declared, Article 21 of the Indian Constitution protects "the right to health, reproductive health and the right to food.... [T] he right to health ... would include the right to access government (public) health facilities and receive a minimum standard of treatment and care. In particular this would include the enforcement of the reproductive rights of the mother and the right to nutrition and medical care of the newly born child and continuously thereafter till the age of about six years."2o

\section{One Case Leads to Another}

According to lawyers who worked on the Laxmi Mandal case, the recognition of a constitutional right to maternal health in India was a turning point: failure to provide adequate care would no longer be mere medical negligence, but a violation of 
a fundamental, justiciable right. ${ }^{21}$ While ensuring implementation of the Court's orders has posed significant challenges, advocates' commitment to leveraging the judgment to improve maternal health nationwide invites hope.

Because the decision came from the Delhi High Court rather than the Supreme Court, it was binding only in Delhi. Nevertheless, the judgment is clearly influencing other High Courts' decisions. For example, in a 2012 case in the rural state of Madhya Pradesh, advocates argued that the poor quality of medical services was contributing to high maternal mortality rates and violating poor pregnant women's constitutional rights. Echoing Justice Muralidhar, the High Court found that the right to survive pregnancy was a fundamental right guaranteed by Article 21. ${ }^{22}$

Moreover, the case compellingly illustrates how courts can help enforce substantive constitutional rights despite government inaction. Months after issuing the decision in Shanti Devi's and Fatema's cases, Justice Muralidhar learned of another woman who died days after giving birth in the street near busy Connaught Place. Dismayed, he contacted the chief justice, urging him to initiate a case sua moto (on his own motion) - a power of the courts established in India as part of the "public interest litigation" permitted by the constitution. ${ }^{23}$ The chief justice agreed and ordered the Delhi government to establish five shelters for poor pregnant and lactating women, with food and medical care available around the clock. Again, the Court grounded its ruling in Article 21: "[W]e . . cannot become the silent spectators waiting for the Government to move like a tortoise and allow the destitute pregnant women and lactating women to die on the streets of Delhi ... giving birth to a child or ... along with the child. Such a situation cannot be countenanced and is not possible to visualize in the backdrop of Article 21 of the Constitution of India." ${ }^{24}$

\section{Health Rights' Growing Role in Addressing Maternal Mortality Globally}

These rulings from India affirm the potential of constitutional rights as tools for addressing preventable deaths and strengthening health protections for some of the most marginalized groups. Moreover, the role of the right to health in promoting accountability for preventable maternal deaths is gaining traction in other parts of the globe. In Uganda, where 16 women die during childbirth every day, a case initiated in 2011 to hold the government accountable for two mothers' preventable deaths, based on the constitutional rights to health, life, and gender equality, was still moving through the court system as of $2018 .^{25}$ Similarly, in Brazil, the family of a woman who died during childbirth brought a claim before the Convention on the Elimination of All Forms of Discrimination Against Women (CEDAW) Committee in 2007, arguing that the government had violated her rights to health and life by failing to provide her timely access to emergency care. ${ }^{26}$ In the firstever decision on maternal mortality by an international body, the committee ruled that the state's responsibility to prevent maternal deaths was "strongly anchored" in Brazil's constitution, particularly five articles addressing the right to health. ${ }^{27}$ 
Through these landmark cases, the right to health has emerged as a critical tool for promoting accountability and reducing preventable deaths worldwide.

As these examples illustrate, constitutional health rights have significant potential to have both individual- and population-level impacts. But how commonly do constitutions guarantee health rights, and where are these rights lacking? Further, is an enforceable constitutional right to health feasible across countries, or will it overburden medical and legal systems? Finally, how can constitutional health rights be most effectively designed and implemented to improve health outcomes for everyone in a country-not just those who make it to court?

\section{HEALTH AS A HUMAN RIGHT:}

\section{GLOBAL FOUNDATIONS}

The first global agreements recognizing health as a human right were drafted in the wake of World War II, as international human rights law was gaining legitimacy globally as a mechanism for maintaining peace and promoting well-being. ${ }^{28}$ In 1945, delegates from around the world began drafting the constitution of the emerging WHO, which opened for signature the following year and defined health as "a state of complete physical, mental and social well-being and not merely the absence of disease or infirmity." ${ }^{29}$

This broad understanding of health is reflected in other U.N. agreements. The 1948 Universal Declaration of Human Rights laid out a similarly comprehensive understanding of health's foundations: "Everyone has the right to a standard of living adequate for the health and well-being of himself and of his family, including food, clothing, housing and medical care and necessary social services, and the right to security in the event of unemployment, sickness, disability, widowhood, old age or other lack of livelihood in circumstances beyond his control." ${ }^{\circ}$

In 1966, the U.N. built on this agreement and adopted the International Covenant on Economic, Social and Cultural Rights (ICESCR), which guarantees the "right of everyone to the enjoyment of the highest attainable standard of physical and mental health," specifically calling on states to fulfill this right through disease prevention, the reduction of infant mortality, and universal access to medical services. ${ }^{31}$ In detailing this right, the U.N. Committee on Economic, Social and Cultural Rights has affirmed that "the right to health embraces a wide range of socioeconomic factors that promote conditions in which people can lead a healthy life, and extends to the underlying determinants of health, such as food and nutrition, housing, access to safe and potable water and adequate sanitation, safe and healthy working conditions, and a healthy environment." ${ }^{2}$

\section{THE NATURE OF HEALTH RIGHTS}

At the national level, what do health rights cover? Do they primarily focus on access to medical care and medicines, as in this chapter's introductory cases, or 
do they also cover crucial aspects of public health that prevent sickness or injury in the first place? For example, does a right to health cover a right to vaccines, which can prevent illnesses; a right to information about and access to measures necessary for preventing the spread of infectious diseases; and a right to the kind of prenatal nutrition and testing that would lower the risk of pregnancyrelated complications?

\section{Accounting for the Full Range of Factors Influencing Health}

This chapter's opening cases illustrate a trend in many countries, wherein most health rights cases brought to court focus on the right to treatment or medical care. Care and treatment are unequivocally important. Yet substantial evidence shows that medical care contributes to a minority of overall health improvements. ${ }^{33}$

Public health measures, from immunization campaigns to effective efforts to lower smoking and traffic accident injuries, profoundly impact health. Similarly, the health of one's environment, including exposure to pollutants or violence, shapes the likelihood of injury and illness. Likewise, social conditions ranging from income, which shapes access to food and other necessities, to access to education, which can shape health literacy, all critically influence health outcomes. This final set of factors is commonly referred to as "the social determinants of health," which WHO defines as "the conditions in which people are born, grow, work, live, and age, and the wider set of forces and systems shaping the conditions of daily life." ${ }^{4}$

\section{The Broad Benefits of Preventive Health Measures-and Risks of Focusing Exclusively on Medical Care}

Given the importance of public and population health approaches to improving health from the get-go, policymakers, civil society leaders, and researchers alike have warned of the risks of any approach to health rights that solely addresses access to medications and medical care.

The problems are twofold. First, prioritizing medical care alone would neglect many of the most effective means of improving individuals', families', and whole countries' health. It makes little sense to pay for young children's hospitalization for diarrheal disease but not for lower-cost sanitation measures that would prevent their illness in the first place. Prevention measures can help far more people, and no one would prefer treatment for a severe illness over the ability to avoid it altogether.

Second, with regard to rights, if courts address only individual treatment for specific illnesses without considering the broader needs for public health, they may shift resources in resource-constrained environments away from critical measures to protect and promote health for all.

To comprehensively address the right to health, constitutions must address both access to health services and the underlying determinants of health, including social determinants like education, poverty, and equality and environmental 


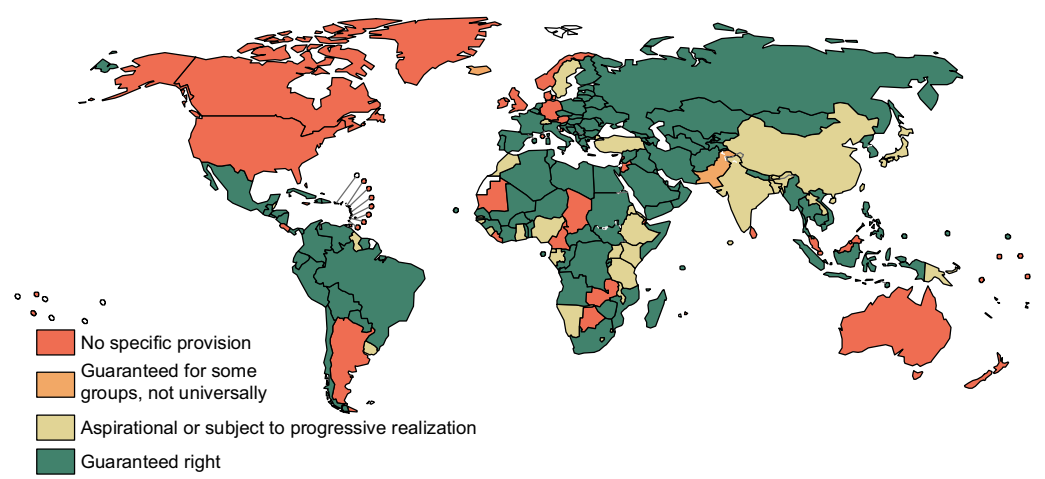

MAP 33. Does the constitution explicitly guarantee an approach to the right to health?

factors like access to clean water and sanitation. Chapters throughout this book address constitutional approaches to some core social determinants of health, including inequality, discrimination, and access to education. This chapter focuses on constitutional approaches to public health, a healthy environment, and healthcare services. In the following section, we examine how often countries guarantee a right to medical care; a broad right to health, interpretable as primarily a right to medical care but potentially extendable to public health; and/or a specific right to public health.

\section{THE RIGHT TO HEALTH IN CONSTITUTIONS}

As of 2017 , nearly $60 \%$ of the world's countries take some approach to guaranteeing the right to public health, overall health, or healthcare services through their constitutions (Map 33). Nineteen percent guarantee the right to public health, compared to $41 \%$ guaranteeing the right to medical care and $36 \%$ guaranteeing the right to overall health. Additionally, $16 \%$ protect health rights in aspirational terms; as with education rights, these provisions commonly describe the right to health as a "goal" or "principle" of the state. Despite providing more modest protections than guarantees, aspirational provisions have catalyzed tangible health improvements, as we explore later. Further, some governments explicitly commit to progressively realizing the right to health as resources increase, consistent with international treaties.

Countries' commitments vary enormously in their level of detail. Some countries, like Cape Verde, delineate how the protection and promotion of health will be accomplished:

1. Everyone shall have the right to health and the duty to defend and promote it, independently of economic condition.

2. The right to health shall be realised through an adequate network of health services and through the creation of economic, social, cultural and environmental conditions which promote and facilitate a better quality of life for the population. 


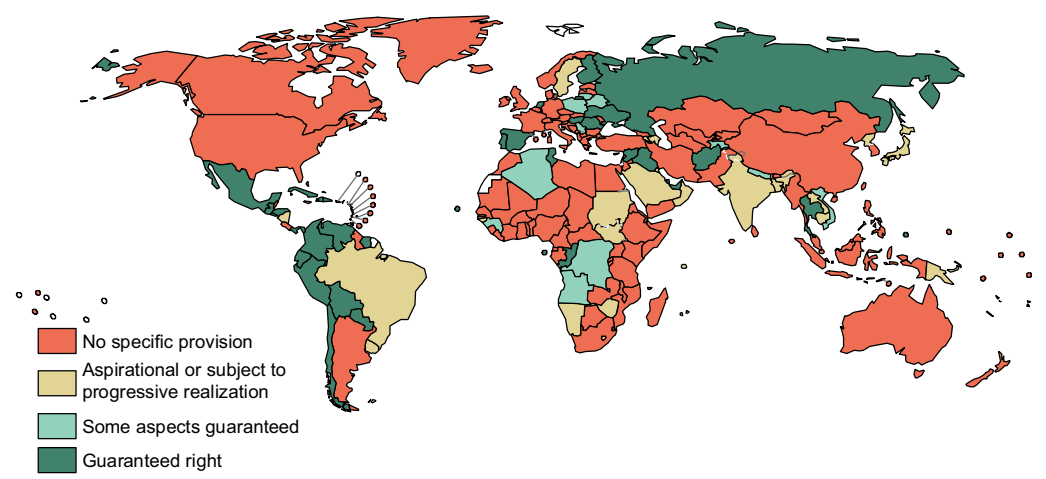

MAP 34. Does the constitution explicitly guarantee citizens' right to public health?

3. In order to guarantee the right to health, the state shall have the following duties:

(a) To assure the existence and functioning of a national health system;

(b) To encourage the community's participation at the various levels of health services;

(c) To assure the existence of public health care;

(d) To encourage and support private initiative in the rendering of preventive, curative and rehabilitative health care;

(e) To promote the socialisation of the costs of medical care and medication;

(f) To regulate and supervise the activity and quality of health care services;

(g) To regulate and control the production, commercialisation and use of pharmacological products, and other means of treatment and diagnosis. ${ }^{35}$

Other countries provide little specificity in describing the state's responsibility. For example, Togo's constitution provides: "The State shall recognize to all citizens the right to health. The State shall strive to promote it." ${ }^{36}$

\section{The Right to Public Health}

Among the $19 \%$ of constitutions guaranteeing the right to public health, the provisions vary widely in scope (Map 34). Some countries' constitutional public health protections primarily focus on preventing the spread of disease. For example, Kuwait's constitution states: "The State cares for public health and for means of prevention and treatment of diseases and epidemics." ${ }^{37}$ Other constitutions, like Venezuela's, provide for broader public health protections: "In order to guarantee the right to health, the State creates, exercises guidance over and administers a national public health system that crosses sector boundaries, and is decentralized and participatory in nature, integrated with the social security system and governed by the principles of gratuity, universality, completeness, fairness, social integration and solidarity. The public health system gives priority to promoting health and preventing disease, guaranteeing prompt treatment and quality rehabilitation. Public health assets and services are the property of the State and shall not be privatized." ${ }^{38}$ 


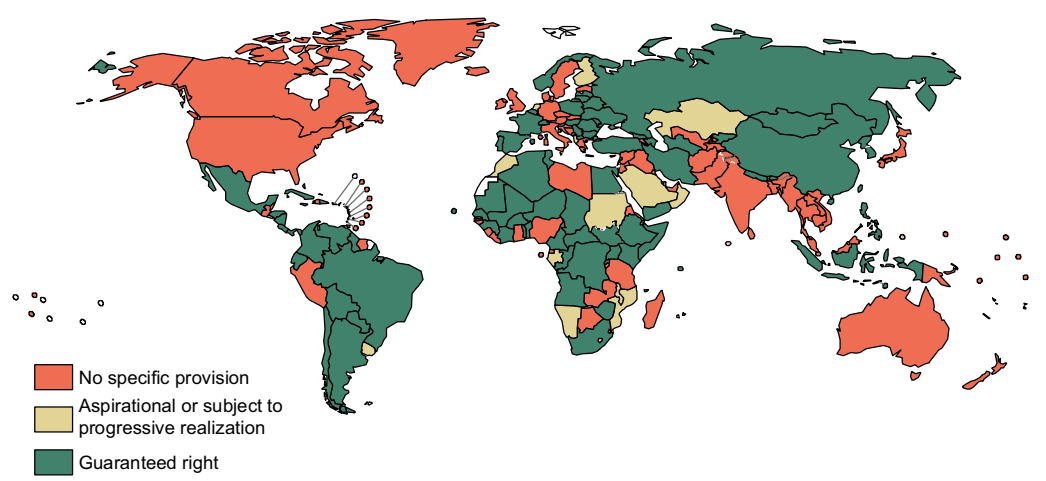

MAP 35. Does the constitution explicitly guarantee citizens' right to a healthy environment?

An additional $6 \%$ of constitutions address public health narrowly by addressing only the duty to prevent epidemics or by providing for specific public health measures. For example, Belarus's constitution provides: "The right of citizens of the Republic of Belarus to health care shall also be secured by the development of physical training and sport, measures to improve the environment, the opportunity to use fitness establishments and improvements in occupational safety." 39 Nine percent of constitutions address reproductive healthcare or maternal health.

\section{The Right to a Healthy Environment}

Although relatively few countries explicitly guarantee the right to public health, nearly half guarantee the right to a healthy environment (Map 35), which is fundamental to health now and for future generations. Some of these provisions focus on health protection, others on environmental conservation. ${ }^{\circ}$ Georgia includes environmental protection in the same article as other health rights:

1. Everyone shall have the right to enjoy health insurance as a means of accessible medical aid. In the cases determined in accordance with a procedure prescribed by law, free medical aid shall be provided.

2. The state shall control all institutions of health protection and the production and trade of medicines.

3. Everyone shall have the right to live in healthy environment and enjoy natural and cultural surroundings. ${ }^{41}$

Belgium's constitution focuses on a healthy environment as one aspect of the "right to lead a life in conformity with human dignity," alongside rights to employment, social security, decent housing, and others. ${ }^{42}$ Ensuring a healthy environment is often framed as both a right and an individual duty. For example, Angola's constitution states that "[e]veryone has the right to live in a healthy and unpolluted environment and the duty to defend and preserve it," and enumerates measures the state must take for environmental conservation. ${ }^{43}$ 


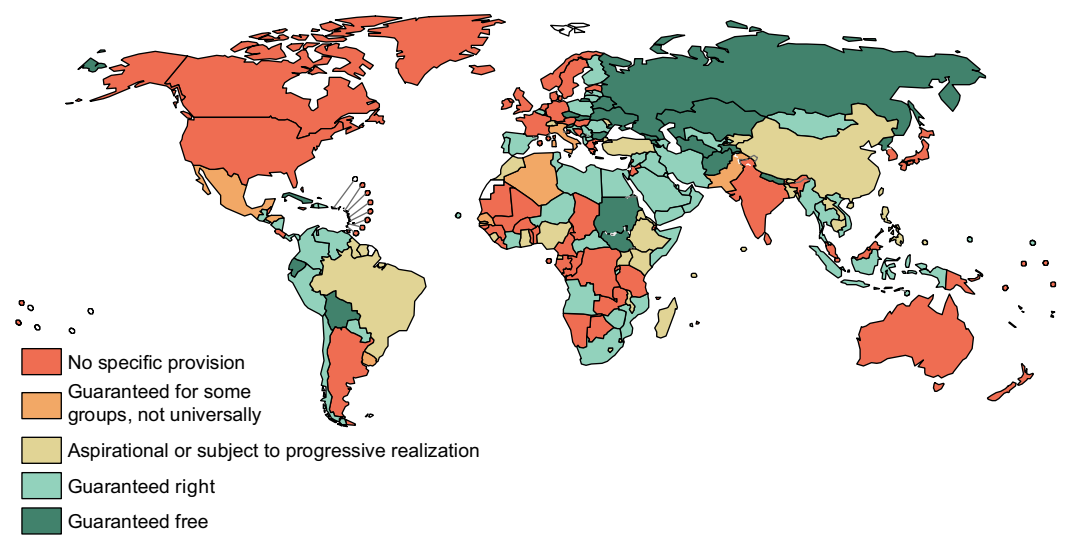

MAP 36. Does the constitution explicitly guarantee citizens' right to medical care?

\section{The Right to Medical Care or Services}

As of $2017,41 \%$ of constitutions guarantee a universal right to medical care (Map 36). Fifteen percent address the medical needs of specific groups (such as children, older residents, persons with disabilities, or people living in poverty), either in addition to a universal right (11\%) or instead (4\%). For example, Nicaragua's constitution guarantees free healthcare "for the vulnerable sectors of the population, giving priority to the completion of programs benefiting mothers and children," 44 while Italy's constitution requires the state to "[provide] free medical care to the poor." 45 Ten percent of constitutions guarantee the right to universal free healthcare; an additional $5 \%$ guarantee free healthcare to one or more groups listed above.

Countries define the right to medical care in varying detail and take different approaches to describing its scope. Some include healthcare under a broader guarantee of social protection or a minimum standard of living for individuals. For example, Romania's constitution states:

(1) The State shall be bound to take measures of economic development and social protection, of a nature to ensure a decent living standard for its citizens.

(2) Citizens have the right to pensions, paid maternity leave, medical care in public health centres, unemployment benefits, and other forms of public or private social securities, as stipulated by the law. Citizens have the right to social assistance, according to the law. ${ }^{46}$

Other countries include more detailed provisions on medical care systems. For example, Bolivia's constitution guarantees the right to health and further pronounces: "There shall be a single health system, which shall be universal, free, equitable, intra-cultural, intercultural, and participatory, with quality, kindness and social control. The system is based on the principles of solidarity, efficiency and coresponsibility, and it is developed by public policies at all levels of the government." ${ }^{47}$ 


\section{The Right to Life}

Some countries guarantee a constitutional "right to life," which in some contexts has been interpreted to include a "right to health" and thus extend similar protections, as illustrated by the introductory case from India. The ambit of this right is wide-ranging. In some countries, the "right to life" is part of the constitution's due process or liberty protections. For example, Canada's constitution establishes: "Everyone has the right to life, liberty and security of the person and the right not to be deprived thereof except in accordance with the principles of fundamental justice." ${ }^{8}$ In others, the "right to life" appears in relation to the death penalty, as in Ghana's constitution: "No person shall be deprived of his life intentionally except in the exercise of the execution of a sentence of a court in respect of a criminal offence under the laws of Ghana of which he has been convicted." ${ }^{49}$ In some, the "right to life" is framed as limiting or negating women's reproductive health options and decision-making, ${ }^{50}$ contradicting international law ${ }^{51}$ and placing women's health at risk. ${ }^{52}$

Overall, of the constitutions lacking a "right to health," approximately threequarters describe life as a value or right. ${ }^{53}$ Because of its wide-ranging meanings explored above, our data on constitutional approaches to health do not capture the "right to life." Nevertheless, depending on its articulation, the right to life can be important for advancing health. In countries whose constitutions include both, the rights to life and to health are commonly invoked together in court; in a study of 71 access-to-medicine cases across 12 Central and Latin American countries, $83 \%$ of successful cases referenced both rights. ${ }^{54}$

\section{Impact of Emphasis on Medical Care}

The numbers show that countries far more often guarantee a right to medical care than a right to preventive healthcare. Moreover, countries that provide a broad right to health have overwhelmingly interpreted it as a right to medical care. Further, courts have often resolved cases focused on an individual's right to medical treatment without considering impacts on the government's ability to fund important preventive measures. ${ }^{55}$

This is not always the case. While South Africa's right to health jurisprudence has largely focused on access to pharmaceuticals and medical care ${ }^{56}$ the constitution's explicit guarantee of broader social rights enables South Africans to claim their rights to adequate housing, food, and other basics essential to health. Notably, the TAC case, the first major success in applying health rights to expand access to medicines, was for a preventive measure. Moreover, the Constitutional Court's general approach of evaluating "reasonableness" rather than ordering specific individual remedies, as we later discuss in more detail, enables the government to evaluate how to balance prevention and treatment in fulfilling the right to health.

Clearly, countries can guarantee rights to both the foundations for healthdecent housing, adequate nutrition, education, and public health-and medical 
care. These are complementary. For example, protecting and fulfilling the right to public health, from essential vaccinations to clean water, lowers the cost of the right to medical care. But to be realized, it requires explicit attention.

\section{IMPACTS OF CONSTITUTIONAL HEALTH RIGHTS}

A critical question for policymakers and civil society members who care about advancing health is whether a constitutional right to health is necessary, or whether a comprehensive social safety net in legislation and policy would just as effectively achieve the goals of fostering healthy environments and ensuring universal quality care. Growing evidence suggests that constitutional health rights have the potential to yield unique additional benefits that strengthen health systems overall.

\section{Protecting and Improving Access to Essential Medicines}

One way that health rights may improve health outcomes is by providing tools for advocacy and improvements in national health systems. For example, constitutions' health rights protections have played notable roles when other policies or international relations have created health threats. In Peru, the constitutional protection of the right to health provided an important basis for trade negotiations with the United States on access to essential medicines, ${ }^{57}$ an important example of the intersection among the right to health, global trade, and intellectual property law that emerges across contexts. ${ }^{58}$ Likewise, in Kenya, HIV-positive individuals successfully challenged portions of a law limiting their access to generic anti-retrovirals, based on their constitutional right to health. ${ }^{59}$ Health rights litigation can also pressure governments into improving policies to avoid being taken to court. In Brazil and Costa Rica, for instance, health authorities decided to include antiretroviral drugs in their public health plans after losing multiple lawsuits calling for coverage of those drugs. ${ }^{60}$

\section{Providing a Foundation for Systemic Improvements}

Brazil also provides an example of a country where the introduction of a constitutional right to health led to broader systemic improvements. Brazil's 1988 constitution made health a fundamental right following two decades of social mobilization. ${ }^{61}$ The provision's introduction had faced strong resistance from politicians wanting to privatize the healthcare system, and the government elected after the constitution's passage continued to resist the idea of a unified national health system. ${ }^{62}$ However, pursuant to the constitutional guarantee, the Sistema Unico de Saúde (SUS) was implemented in 1992. Today, approximately $70 \%$ of Brazilians are exclusive users of SUS, which has become the world's largest free public health system. ${ }^{63}$ Additionally, in 2000, a constitutional amendment guaranteed funds to finance health and public services. ${ }^{64}$ Over the following decades, wide-ranging 
studies have found SUS to be associated with significant decreases in hospitalizations and infant and child mortality. ${ }^{65}$

Some countries without a constitutional right to health have achieved widely accessible, high-quality healthcare through strong social service provision. Denmark, for example, has a strong public healthcare system but no constitutional right to health; its constitution was adopted in the 1950s, when constitutions less commonly included health rights. ${ }^{66}$ In Brazil, however, the constitutional right to health catalyzed this change.

\section{Improving Health Outcomes over Time}

Two studies have quantitatively documented the relationship between a constitutional right to health and improved population health outcomes for large numbers of countries. One difference-in-differences study of 157 countries from 1970 to 2007 found that introducing a justiciable constitutional right to healthcare reduced the under-five mortality rate by $5 \%$-increasing to $8.7 \%$ for countries with high levels of democratic governance-after controlling for women's education levels, country GDP, and country and year fixed effects. ${ }^{67}$ Using a difference-indifferences approach and individual-level data on more than 400,000 births in 15 Latin American countries, another study by the same author found the enactment of a constitutional right to health or healthcare to be associated with a $2.6 \%$ subsequent reduction in infant deaths among poor mothers, but not the population as a whole, after controlling for other constitutional economic and social rights and both country-level and child-specific factors. ${ }^{68}$

\section{Supporting the Expansion of Life-Saving Public Health Interventions}

Finally, constitutional health rights, including the right to a healthy environment, can provide a powerful legal basis for enacting life-saving public health measures, including immunization campaigns. For example, in Argentina, a woman went to court in 1998 to urge the government to complete production of the vaccine against Argentine hemorrhagic fever, a potentially deadly disease that put over 3.5 million people at risk, especially in rural areas. In 1991, Argentina had begun producing the vaccine, which was shown to be $95 \%$ effective, but discontinued production before the vaccine was made publicly available. In its ruling, citing Argentina's commitments to health rights in both international treaties and the constitution, the Court ordered the government to complete production according to a specific timeline. ${ }^{69}$

Similarly, that same year in Colombia, over 400 parents from a poor part of Bogotá filed a lawsuit demanding that the government provide their children with a free meningitis vaccine, citing their constitutional rights to health, life, and social security..$^{70}$ The minister of health had previously stated that a new program would make the vaccine freely available in poor neighborhoods, but the program had not been implemented. Meanwhile, many of the petitioners' children were attending 
crowded daycares while their parents worked, putting them at high risk of contracting the disease, while the vaccine's cost made it inaccessible. ${ }^{71}$ Citing the constitution's right to health, along with its provision allowing affirmative measures for marginalized groups, the Court ordered the Ministry of Health to immediately implement the free vaccine program, underscoring that it "[could not] accept that indigent children or those whose parents do not have sufficient resources, have to face the risks that are products of terrible diseases and the inaction of public health administrations." ${ }^{2}$

Health rights have also provided foundations for improving nutrition, ${ }^{73}$ upholding restrictions on exposure to tobacco, ${ }^{74}$ and strengthening other public safety and environmental health measures. ${ }^{75}$ Catalyzed by the constitutional right to health, these improvements have collectively saved countless lives.

\section{THE FEASIBILITY AND EFFECTIVENESS}

OF A RIGHTS APPROACH

Questions about a constitutional right to health commonly surround the economic and judicial challenges of implementation. While this issue emerges across social and economic rights, the right to health, perhaps more than any other, raises questions about the level of government investment required for fulfillment. While challenging for all countries, this question is most pressing for low-income countries. The judicialization of the right to health also has implications for courts and for equity: if too many health cases come before the courts, the judicial system's overall efficiency may decrease, and if the only people bringing those cases and benefitting from their rulings are those who can afford private lawyers, the right to health may undermine rather than advance health equity.

\section{Economic Questions: Affordability for the Government}

Although the issue of limited resources is more acute in low-income countries, similar debates emerge in courts across middle- and higher-income contexts. In a 2010 case from Latvia, in which a plaintiff challenged the cap on reimbursement for a drug used to treat leukemia, the Riga District Court ruled that the compensation limit was necessary "to provide as large [a] part of society as possible [the] right to health," citing the constitution's guarantee of "a basic level of medical assistance for everyone." ${ }^{6}$ Likewise, in a case about dialysis, South Africa's Constitutional Court reasoned: "There will be times when [fulfilling health rights] requires [the Court] to adopt a holistic approach to the larger needs of society rather than to focus on the specific needs of particular individuals within society." 77

The principle of progressive realization offers an approach to drafting and interpreting constitutions that shows promise for both broadly advancing health rights and ensuring that governments of all resource levels can manage costs. This principle rests on the acknowledgment that many countries will need time for further 
economic development before they can fully guarantee access to comprehensive medical care for all residents. Nevertheless, all countries can begin to fulfill the right to health; public health can provide a tool for preventing illness for entire populations and reducing future healthcare costs.

\section{Progressive Realization}

Under many international human rights agreements, like the ICESCR, countries are only allowed to "progressively realize" rights that are likely to involve more significant financial costs, like the right to health. While ratifying countries agree to devote the maximum available resources and take immediate concrete steps toward realizing these rights, fulfillment is expected to grow over time as resources increase.

At the same time, low-cost steps and the guarantee of nondiscrimination are understood as immediate obligations. ${ }^{78}$ Further, the U.N. has articulated a set of core, "nonderogable" obligations states must meet to fulfill the right to health, including, at minimum, the provision of essential primary care; access to adequate food, water, and shelter; the provision of essential medicines; and the execution of a public health plan to meet the needs of the whole population. ${ }^{79}$ In practice, the line between specific state actions with respect to health that are subject to progressive realization and those that must be realized immediately is subject to debate within courts and among advocates. Further, as later sections explore, courts' determinations about how to operationalize these concepts to both protect individual rights and ensure the health of the population as a whole vary around the world.$^{80}$ Some countries have directly embedded the idea of progressive realization in their constitutions' approaches to articulating the right to health. For example, South Africa's constitution provides that "[e]veryone has the right to have access to ... . health care services, including reproductive health care," but clarifies within the same article that "the state must take reasonable legislative and other measures, within its available resources, to achieve the progressive realisation of each of these rights." ${ }_{1}$

In others, although the right is "guaranteed" constitutionally, courts interpret the right through a progressive realization lens. For example, Peru's constitution provides that "[e]veryone has the right to protection of his health" and that " $\mathrm{t}] \mathrm{he}$ State guarantees free access to health benefits." ${ }^{82}$ In practice, however, Peru's Constitutional Court has held that "the enforceability of a social right always depends on three factors: a) the seriousness and reasonableness of the case, b) its relationship with other fundamental rights, and c) budget availability." ${ }^{3}$

Kenya's constitution not only spells out a commitment to progressively realizing the right to health, but also explicitly articulates what courts must consider when the government has indicated it lacks sufficient resources to fulfill an aspect of the right. Article 43 provides that "[e]veryone has the right to the highest attainable standard of health, which includes the right to health care services, including 
reproductive health care," and guarantees that "[a] person shall not be denied emergency medical treatment." Article 21, however, establishes that these rights are subject to progressive realization, while Article 20 articulates a set of principles for courts evaluating Article 43 claims:

(a) it is the responsibility of the State to show that the resources are not available;

(b) in allocating resources, the State shall give priority to ensuring the widest possible enjoyment of the right or fundamental freedom having regard to prevailing circumstances, including the vulnerability of particular groups or individuals; and

(c) the court, tribunal or other authority may not interfere with a decision by a State organ concerning the allocation of available resources, solely on the basis that it would have reached a different conclusion.

Globally, all countries can afford to do something to protect and promote the right to health. In fact, low- and middle-income countries more commonly take constitutional approaches to this right than their high-income counterparts (see Figures 14-16). By committing to progressive realization, either directly in constitutional text or through court doctrine, countries can effectively advance health rights in step with their economic development.

\section{The Impact and Importance of Addressing Public Health}

The right to public health, by its very nature, has broad population benefits, and by helping prevent the spread of disease, its implementation can reduce health costs down the line. Courts have demonstrated the feasibility of enforcing rights to public health, including when they are phrased as aspirational or progressive commitments.

For example, in Bangladesh, a former Member of Parliament brought a suit against the government for failing to prevent arsenic contamination of wells across the country, which had put millions at risk of poisoning. The appellant argued that this negligence violated the constitutional rights to health and to life.

Under Article 18(1) of Bangladesh's constitution, located in the section on "fundamental principles of state policy," "[t]he State shall regard the raising of the level of nutrition and the improvement of public health as among its primary duties." ${ }^{4}$ Although this language did not rise to the level of a guarantee, the Court still held that the government's noncompliance with laws on safe drinking water amounted to a violation of its duty to promote health, as well as the right to life, the right to protection of the law, and the state's responsibility to provide basic necessities (another aspirational provision). ${ }^{85}$ Consequently, the Court ordered the government to undertake extensive measures to comply with the law, test for arsenic in wells in affected areas, prevent further contamination, and initiate a media campaign to increase public awareness of the risks of arsenic contamination and provide information about how to find safe, clean water. ${ }^{86}$ 


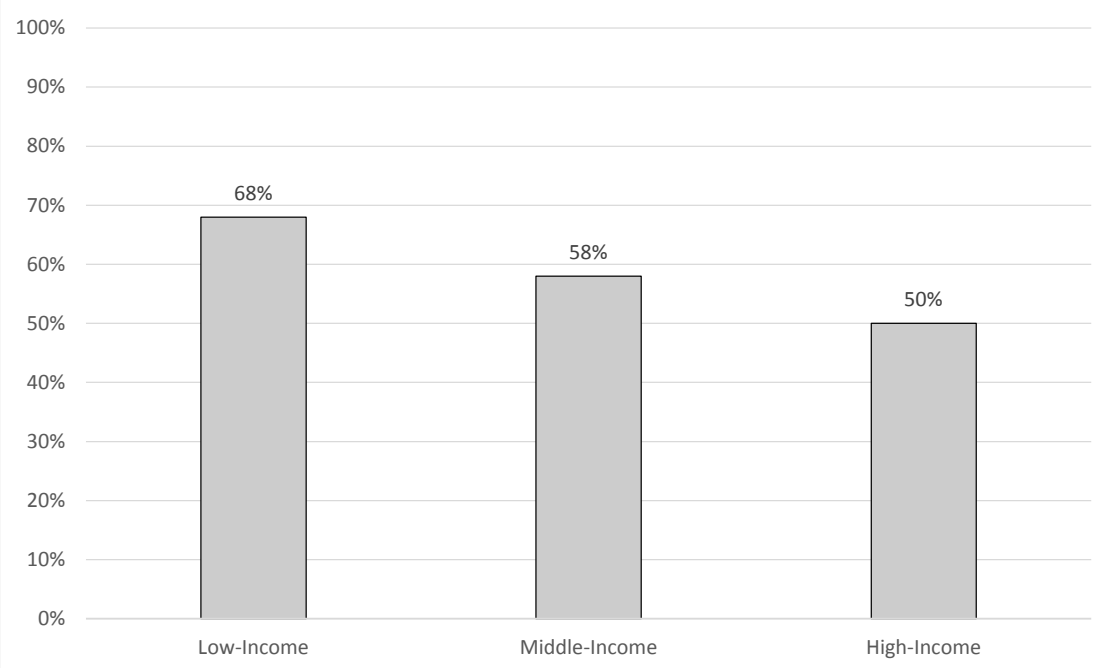

FIGURE 14. Explicit constitutional approach to protecting the right to health by country income group

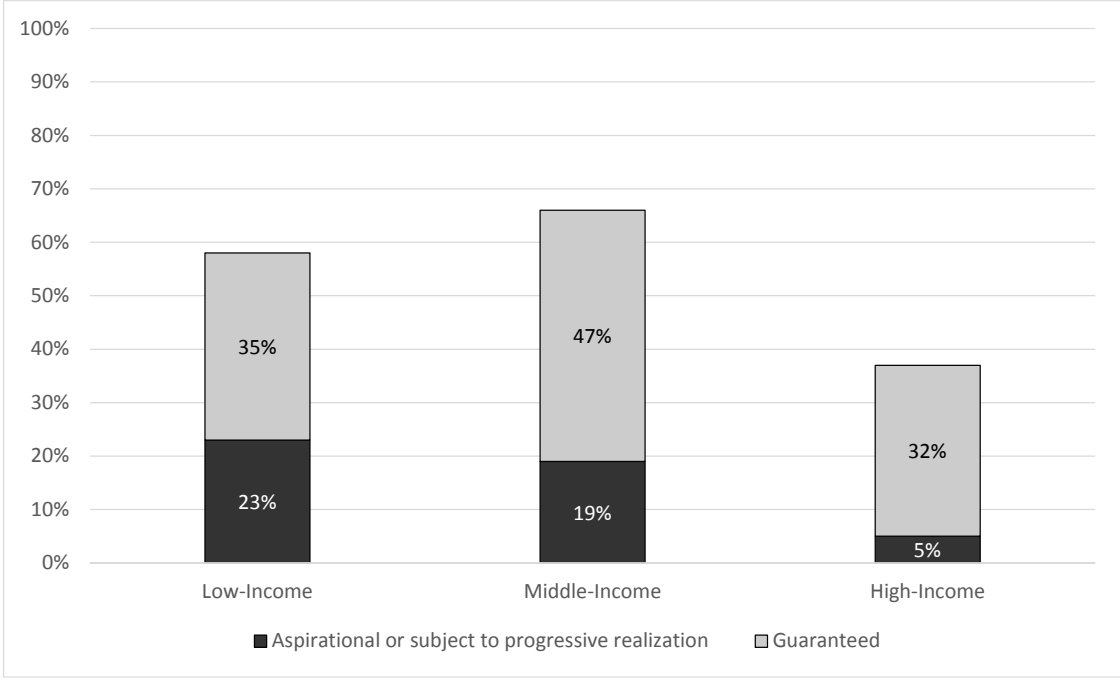

FIGURE 15. Explicit constitutional protection of the right to medical care by country income group 


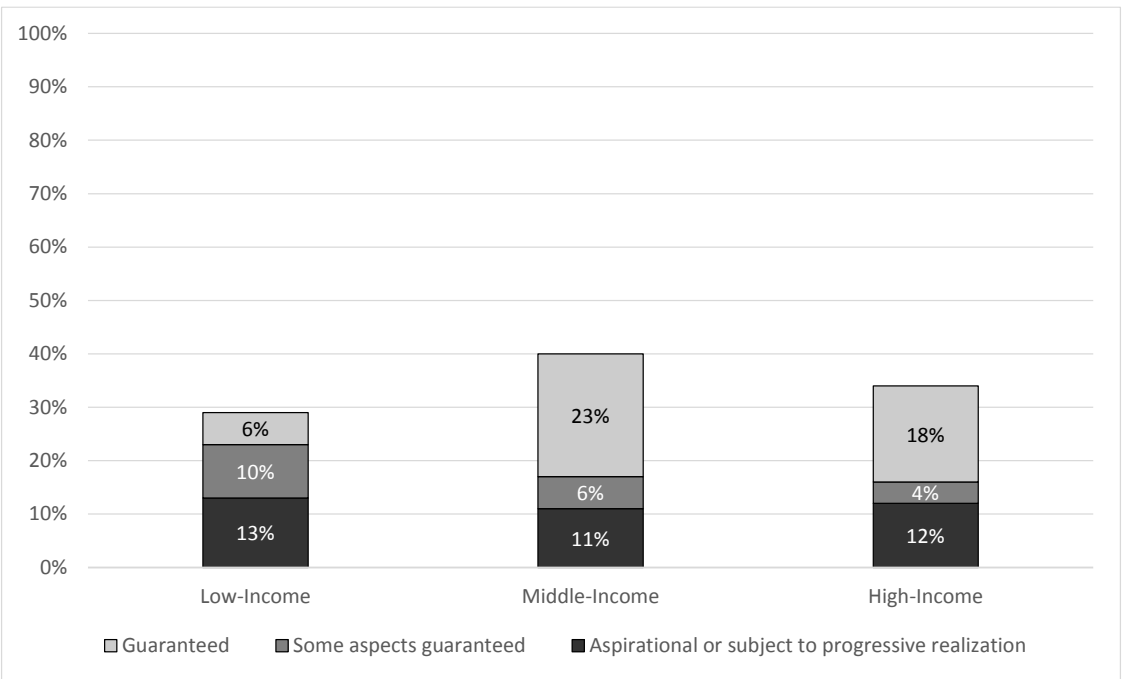

FIGURE 16. Explicit constitutional protection of the right to public health by country income group

Similarly, in India, residents of Ratlam, a Madhya Pradesh city, brought a case before the Supreme Court in 1980 arguing that the Municipal Council had violated their rights to health by failing to provide adequate sanitation, particularly by allowing septic fluids and overflow from an alcohol factory to flow in the streets. ${ }^{87}$ Like Bangladesh's Article 18, Article 47 of the Indian Constitution, which is a "directive principle" rather than an enforceable right, provides: "The State shall regard the raising of the level of nutrition and the standard of living of its people and the improvement of public health as among its primary duties." Although ordered by a lower court to construct a drainage system, the Council had argued they did not have sufficient funds to do so. However, the Supreme Court, citing Article 47, ruled that this excuse was insufficient: "A responsible municipal council constituted for the precise purpose of preserving public health and providing better finances cannot run away from its principal duty by pleading financial inability." As a result, the Court ordered the Municipal Council to improve sanitation infrastructure based on a plan produced by engineers affiliated with both parties to the case, and ordered the Madhya Pradesh government to loan funds to the council to ensure the improvements were financially feasible. ${ }^{88}$

These two cases further underscore why the right to public health, though underrecognized in constitutions, has particularly transformative potential. In both India and Bangladesh, waterborne diseases are among the leading causes of death for young children; ${ }^{89}$ leveraging public health rights to improve sanitation can therefore powerfully affect entire communities. Given their broad and 
demonstrated impact, and the fact that governments are often best positioned to advance public and population health, ensuring constitutions contain commitments to public health should be a priority. Currently, the share of countries with constitutional provisions protecting public health falls far behind the share protecting the right to medical care, even as public health and prevention would reduce poor health, illness, and injury at a far lower cost than medicine can treat them.

\section{Judicial Questions: Implementing Rights for All Regardless of Income}

Across social and economic rights, judicial rulings that are likely to change conditions for entire groups of people, rather than one individual at a time, have the greatest potential to effectively realize these rights without clogging the courts..$^{\circ}$ Collective actions and judgments are also often better vehicles for equity, particularly since litigation costs can make individual justice through the courts inaccessible to the poorest. The right to health is no exception. ${ }^{91}$ While public health rights are collective by nature, the collective impact of medical care litigation depends largely on the reach of the court's decision. While individual claims to access a particular medicine or treatment can powerfully shape one person's life, collective claims or decisions expanding access for an entire class can be transformative for society.

However, litigants' ability to make claims collectively, or on behalf of a group, varies across countries. Likewise, the effects of courts' rulings on future judicial decisions depend partly on countries' legal traditions. As previously noted, the two major traditions are common law, which has origins in the United Kingdom and remains prevalent across former British colonies, and civil law, which began in continental Europe and today also applies throughout much of South America and East Asia. Many countries incorporate elements from both traditions and may also integrate aspects of customary or religious law; generally, however, one tradition is dominant. ${ }^{22}$

A key difference between the two is that common law systems rely heavily on court precedent, whereas civil law systems are based almost exclusively on codified law. As a result, in predominantly civil law countries, prior court decisions are not binding on all subsequent cases. Meanwhile, in predominantly common law countries, precedents typically dictate future decisions, making a series of repetitive claims less likely. Furthermore, in civil law countries, usually only a specialized court (typically the Constitutional Court), or a small number of specialized courts, can declare a law unconstitutional. ${ }^{93}$ This requirement aligns with the limited role of precedent, since otherwise courts at all levels could rule inconsistently about constitutionality. By contrast, in the United States and some other common law countries, "ordinary" courts are empowered to rule on constitutionality, but decisions from higher courts are controlling. ${ }^{94}$ These and other procedural aspects of countries' judicial systems, such as the rules of standing, have implications for the most effective approaches to realizing the right to health for all. ${ }^{95}$ 


\section{Collective Claims across Contexts}

For the right to health, issues of individual versus collective claims are often at the core of questions of justiciability, including whether courts have the capacity to both hear all claims brought before them and issue effective remedies. Across countries, the ease of bringing class actions and other types of collective lawsuits varies. Some notable examples follow.

The U.S. was among the first countries to introduce a class action lawsuit, which allows a group of people experiencing the same legal issue, including constitutional rights violations, to bring a claim together and pursue a remedy that will apply to all. A U.S. class action requires a "class representative" who was personally harmed by the challenged law or action. ${ }^{96}$ Once a class action is decided, people who were members of the class, or were eligible to be members but opted out, cannot bring individual claims based on the same allegations, regardless of how the court rules. If the class wins the case, all of its members are typically entitled to monetary damages or other relief. The U.S. also allows for punitive damages, meaning defendants can be required to pay compensation to the class that exceeds mere restitution, as well as attorneys' fees, which increases the incentive for lawyers to bring class action cases.

While it has been criticized as making the U.S. a more litigious society, the class action has yielded some significant victories for health. For example, in 1997, facing the threat of numerous class actions nationwide, the four largest tobacco companies paid over $\$ 200$ billion to reimburse 46 states for public health costs attributable to smoking, and agreed to discontinue their deceptive marketing practices. ${ }^{97}$ It is estimated that the settlement, which also resulted in tobacco companies raising their prices, reduced the share of 18 - to 20 -year-olds who smoked by $13 \%$ over the next four years, and 21 - to 65 -year-olds by $5 \% .{ }^{98}$

Likewise, in countries like India and Bangladesh, as discussed in chapter 8, public interest litigation (PIL) has provided a powerful tool for securing legal remedies with population-wide benefits. ${ }^{99}$ While similar, an important distinction between PIL and the traditional class action is the standing requirement: for a PIL action, any concerned community member can initiate the lawsuit, even if they have not been directly harmed.

This aspect of PIL has enabled important rulings on behalf of vulnerable groups who might otherwise struggle to access the courts. For example, in 1985, a lawyer brought a case on behalf of child laborers in match factories in Tamil Nadu, India, arguing that their work in dangerous conditions violated constitutional rights including the (aspirational) right to public health. ${ }^{100}$ In a sweeping order, the Supreme Court addressed the obligations of the government, employers, and parents in realizing the constitutional prohibition on child labor, and in subsequent years India strengthened its child labor laws. ${ }^{101}$

In many civil law countries, particularly in Latin America, individuals enjoy remarkably straightforward access to the courts, though collective actions are less well established. Specifically, the amparo and acción de tutela are two "fast-track" 
mechanisms common throughout the region that allow any individual to go to court to immediately enforce their fundamental rights. ${ }^{102}$ Notably, some countries, such as Argentina, allow groups of individuals represented by an NGO to bring an amparo together, thus facilitating both quick court access and a more efficient path to justice. ${ }^{103}$ While full implementation of judicial orders in Argentina's collective cases has not yet been realized, ${ }^{104}$ this mechanism, dubbed the amparo colectivo by some, has been instrumental in advancing more structural changes, including with respect to HIV/AIDS treatment. ${ }^{105}$

However, across civil law countries, traditional class actions remain rare. ${ }^{106}$ One exception is Brazil, which introduced a class action through a 1985 statute. By contrast to the U.S. model, however, a group seeking to bring a class action in Brazil must be represented by an NGO or government body, such as a municipality. ${ }^{107}$ Further, the "notice" requirement-whereby potential class members learn of the lawsuit-requires only a single publication in a newspaper. ${ }^{108}$ Finally, the action itself establishes the defendant's liability, but each class member must still initiate individual proceedings to claim damages, typically limited to compensation for actual harms. ${ }^{109}$ Consequently, the Brazilian class action as currently designed may not be as accessible or impactful as possible.

Further, despite the class action's availability in Brazil, the collective approach is largely underutilized, at least with regard to health rights-perhaps because litigants prefer the amparo's simplicity. According to legal scholar Alicia Ely Yamin, the combination of unusually easy individual access to the courts in Latin America and the one-off nature of most courts' decisions has produced "high levels of individual litigation for treatments and services, which as a general matter exploit the system but do not attempt to transform it." ${ }^{110}$ Indeed, across Brazil, just 3\% of "right to health" suits against the federal government are collective. ${ }^{111}$ This apparent preference may also reflect pragmatic considerations of the odds of winning: data on the top Brazilian courts' decisions reveal that claimants in individual "right to health" cases are far likelier than those bringing collective suits to be successful, possibly reflecting judges' more conservative approach to cases that would have sweeping impacts or significant budgetary implications. ${ }^{112}$

Regardless, as individual health rights cases have become increasingly common, the courts have become overburdened and have experienced a significant backlog. ${ }^{113}$ In Rio de Janeiro, the number of "right to health" cases filed skyrocketed from a single lawsuit in 1991 to 1144 in 2002. ${ }^{114}$ Similarly, in Colombia, the right to health was "the most commonly litigated right" between 1999 and 2011, accounting for 869,604 out of $2,725,361$ total cases. ${ }^{115}$ In 2008 alone, one in every 300 Colombians filed a health-related tutela. ${ }^{116}$ Observers feared that the "high volume of rights litigation [could] challenge the very sustainability of a public healthcare system and distort resources away from those most in need," ${ }^{117}$ while potentially undercutting the tutela's legitimacy. ${ }^{118}$ 


\section{Collective Judgments in Colombia and South Africa}

As noted, to some extent, courts' ability to issue decisions with far-reaching effects depends on the role of precedent within their particular legal system. In countries where prior decisions are not binding on future cases, it is not unusual for courts to hear a series of similar claims. However, courts can also shape their decisions' impact by how narrowly or broadly they resolve the issue before them. Both civil law and common law courts have demonstrated the feasibility of deciding cases to have more structural effects.

For example, in Colombia, the aforementioned volume of individual claims culminated in a 2008 Constitutional Court ruling addressing the health system's "structural failures," including inadequate regulation of the insurance companies that should have been covering many of the medicines and treatments sought through the courts. ${ }^{119}$ The landmark decision "called for significant restructuring of the health system based on rights principles, including non-discrimination, participation, and accountability." ${ }^{120}$

While the impact of the Court's decision is still unfolding, its efforts to address the systemic issues that have engendered the high volume of litigation provide one example of how judges even in civil law jurisdictions can shape their rulings to have larger collective impact. ${ }^{121}$ In 2015 , the legislature enacted a new statute aimed at implementing the ruling, recognizing the fundamental right to health and articulating new rules for insurers and health providers. ${ }^{122}$ Meanwhile, individual health claims before the Court have been declining: health rights accounted for $42 \%$ of all tutela claims in 2006 , falling to $24 \%$ by $2014 .{ }^{123}$

Over the past two decades, the Constitutional Court in South Africa, a predominantly common law country, has illustrated the feasibility of effectively adjudicating social and economic rights, even in a lower-resource setting, by focusing on the reasonableness of the government's overall decision-making process rather than each plaintiff's specific circumstances. ${ }^{124}$

Justice Albie Sachs discussed the considerations in a controversial right to health case decided by the Court, in which a man with kidney failure, Thiagraj Soobramoney, was seeking further treatment from a state hospital. ${ }^{125} \mathrm{He}$ had already received emergency treatment at the state hospital once, and was told then that in the future he would have to wait his turn to receive treatment, in accordance with hospital policies establishing very strict criteria for determining which patients' treatment was prioritized, given limited resources. The Court found that the hospital

had applied criteria that were compatible with constitutional standards and values, that they used rational grounds for deciding who should have access to emergency treatment, and that the selection process used was not discriminatory, except on pure health grounds (which was relevant as criteria); therefore, we could not order the hospitals to act otherwise. To move him head of the queue would be to prejudice other people who had greater health claims, by saying that government must take 
money away from dealing with HIV, immunization for children, health education programs, victims of trauma, and all other diseases that we have such as cancer and tuberculosis. We decided that, as judges, we could not interfere with the priorities in that particular area, and could not say that the hospital's expenditure and way it was utilized did not meet constitutional standards. ${ }^{126}$

In this case, rather than narrowly evaluate the facts of a particular plaintiff's claim, the Court evaluated the reasonableness and fairness of the government's action (or inaction) and whether the government had established a reasonable, nondiscriminatory process for making decisions about the use of limited healthcare resources. In 2013, a Kenyan High Court reached the same conclusion in an almost identical dialysis case, applying its constitution's criteria for progressive realization and directly citing the Soobramoney ruling. ${ }^{127}$ These decisions thus back the view that courts can effectively support progressive rights realization by ensuring that "public decision-makers follow a fair process in decision making, weighing the interests of individual needs with the importance of fairly distributing limited public resources across the whole population." ${ }^{128}$

However, this is not to say the "reasonableness" approach provides a perfect solution, or has been immune from criticism. To some, addressing "reasonableness" falls short of requiring the government to fulfill a "minimum core" of the rights to health, housing, or other socioeconomic rights; ${ }^{129}$ some courts, such as Germany's Constitutional Court, have applied a "reasonableness"-like test that also takes into account minimum standards, which may better ensure meaningful assessment of both the government's process and what it takes to fulfill the right at hand. ${ }^{130}$ Others argue that it requires courts to defer too much to the executive and legislative branches, thereby limiting constitutional rights' potential as a check on government inaction. ${ }^{131}$ Finally, despite being premised on fairness, the "reasonableness" approach may not always bring justice to each individual, especially if inadequate attention is devoted to implementation. ${ }^{132}$

Yet for those who question whether courts can address health rights in the first place, South Africa's approach provides an example of judicial decision-making that takes collective concerns into account. Further, while the nature of the challenge varies across contexts, cases from wide-ranging countries have shown that the right to health can improve health on a large scale. Even in civil law countries, collective "right to health" challenges and court actions to initiate broad improvements to health systems have yielded benefits to significant numbers of people. Continuing to identify effective strategies for leveraging health rights to advance collective well-being across different constitutional systems will be important for ensuring their full impact.

\section{PROGRESS ON HEALTH RIGHTS AND IMPLICATIONS FOR BROADER EQUALITY}

Over the past few decades, a growing number of constitutions and courts worldwide have begun recognizing - and enforcing — the right to health, which has 


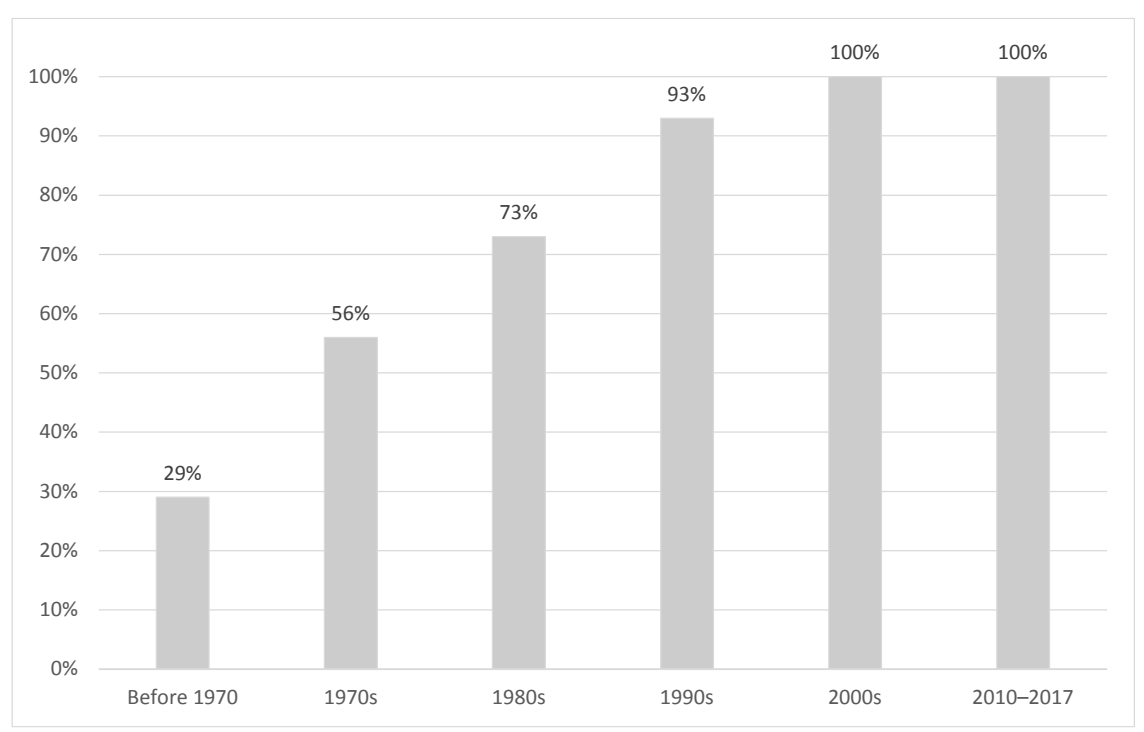

FIGURE 17. Explicit constitutional approach to protecting the right to health by year of constitutional adoption

assumed new importance in shaping citizens' access to public health and medical services. Despite the complexities explored in this chapter, the right to health has both yielded tangible impacts for individuals and populations, and provided the basis for structural improvements to national health systems.

Like other social and economic rights, explicit constitutional protections of health rights have become more common over time. Only $29 \%$ of constitutions adopted before 1970 took an approach to health, while all constitutions adopted in 2000-2017 included the right to health, public health, and/or medical care (see Figure 17). Among newer constitutions, health is emerging as a priority area: all four of the constitutions newly adopted following the Arab Spring, in Egypt, Tunisia, Libya, and Yemen, guaranteed an approach to health, which some view as a step toward universal health coverage..$^{133}$

Still, more is needed, especially with regard to public health. While $57 \%$ of highincome countries, $76 \%$ of middle-income countries, and $94 \%$ of low-income countries have enacted some constitutional approach to health, only $19 \%$ across income groups take an approach to the right to public health. The persistence of preventable diseases and death evidences the grave need for further action: despite recent progress, around 5.9 million children die before age five each year, ${ }^{134}$ while over three times as many lack key immunizations. ${ }^{135}$ Maternal mortality also remains indefensibly high, with approximately 830 women dying each day ${ }^{136}$ Health disparities based on gender, socioeconomic status, race, and other characteristics and statuses compound other inequalities, demonstrating the need for both uni- 
versal access to public health and healthcare and strong protections against all forms of discrimination. Countries that have already enshrined health rights in their constitutions can provide insight into effective approaches to drafting and implementing rights to health elsewhere. For the 51 countries that have yet to do so, establishing a constitutional right to health would be an important step toward strengthening the human right to health and reinforcing countries' accountability to their citizens' well-being. 